\title{
Regioselective Mitsunobu-tosylation of 1,2-diols
}

\author{
Chorom Kim, Ji Eun Keum, Sang Hee Yu, and Soo Y. Ko \\ Department of Chemistry, Enha Homans Linersity, Seoul 120-750, Korea. E-mail: soovoátewhackr \\ Received Mav 29, 2009, Accepted Jume 5, 2009
}

Key Words: Mitsunobul-toșylation. 1.2-Diols. Regioselectivity. Stereochemistry

In the course of our study toward a total synthesis of Tamiflul ${ }^{\text {(1) }}$. we needed to convert a 1.2-diol to the corresponding 1-phenylthio-2-ol compound (Scheme 1). ${ }^{\text {l }}$ We achieved this transformation in two steps, as one would usually do it: a regioselective tosylation of the primary hydroxyl group. followed by a nucleophilic substitution with thiophenoxide. The first step. a seemingly straightforward reaction. however. revealed some limitations. Under carefully controlled conditions with $\mathrm{TsCl} / \mathrm{py}$ ridine. the desired l-tosylate product was surely formed as the major product. When the formation of the product reached about a half-way point. there started to appear on TLC the formation of the di-tosylate product. obviously at the expense of the desired mono tosy late. Upon the termination of the reaction. the desired 1-tosylate product was isolated in $53 \%$ yield. along with the di-tosylate in $5 \%$. the rest being the unreacted starting diol.

These results are probably not much different from what others have observed in similar cases. They are certainly not satisfactory but have been put up with due to high recovery ratios. ${ }^{3}$ In the above example, we didn't observe any mono 2-tosylate formed, so the regioselectivity appeared to be very ligh the substituent at C-3 presumably exerting its effects against the reaction at $\mathrm{C}-2$ hydroxyl group at the initial stage of the tosylation reaction when both hydrosyl groups were available for reaction with $\mathrm{TsCl}$. Without any bias at $\mathrm{C}-3$. the regioselectivity is not expected to be so high. as we have confirmed in model reactions (Scheme 2). Thus, under standard reaction conditions. alkane-1.2-diols underwent tosylation to produce a mixture of the following products: mono-1-tosy late $(45-50 \%)$ : mono-2-tosylate (10-15\%): di-tosylate $(5-15 \%)$.

The two regioisomeric mono tosy late compounds were not easy to separate from each other on column chromatography. This fact can cause a serious problen, when the mono tosylation of a 1.2-diol substrate is performed, to be followed by a mucleophilic substitution at the C-l, as is often the case (Scheme 1. for exanple)

Assume a mono tosylation reaction of a 1.2-diol where the regioselectivity is not very high (ca. $4: 1$. as in Scheme 2). A subsequent nucleophilic substitution may take place directly at the activated carbon. or it may take place under basic conditions in two tandem steps wia epoxide as the intermediate (Scheme 3). With the major mono-1-tosy late compound either pathway leads to the sane (and desired) 2-hydroxy-1-substituted product. With the minor mono-2-tosylate compound. the direct pathway results in the fonmation of 1-hydrosy-2substituted product, a regioisomer with respect to the desired<smiles>CC(C)C1CCC(=O)O1</smiles><smiles>N[C@H]([C@H](O)CO[Na])[C@@H]1CCC(=O)O1</smiles><smiles>N[C@H](COS(=O)(=O)[O-])[C@H](N)C1CCC(=O)O1</smiles><smiles>[13CH3][C@@H](O)[C@@H]1CCC(=O)O1</smiles>

Scheme 1

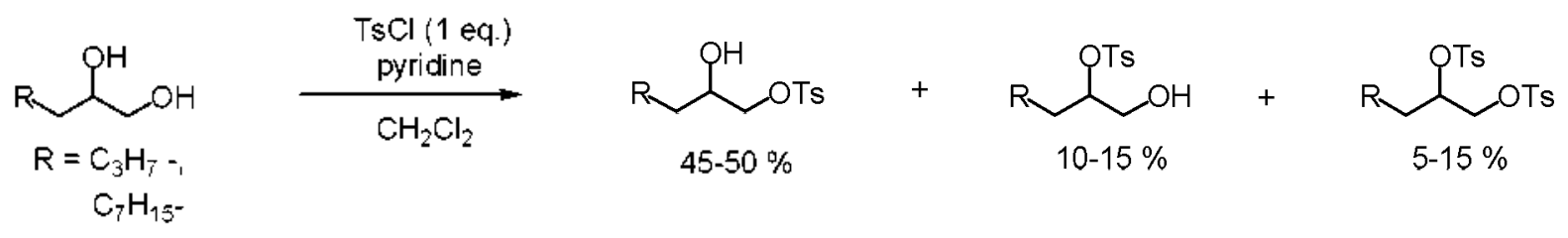

Scheme 2 


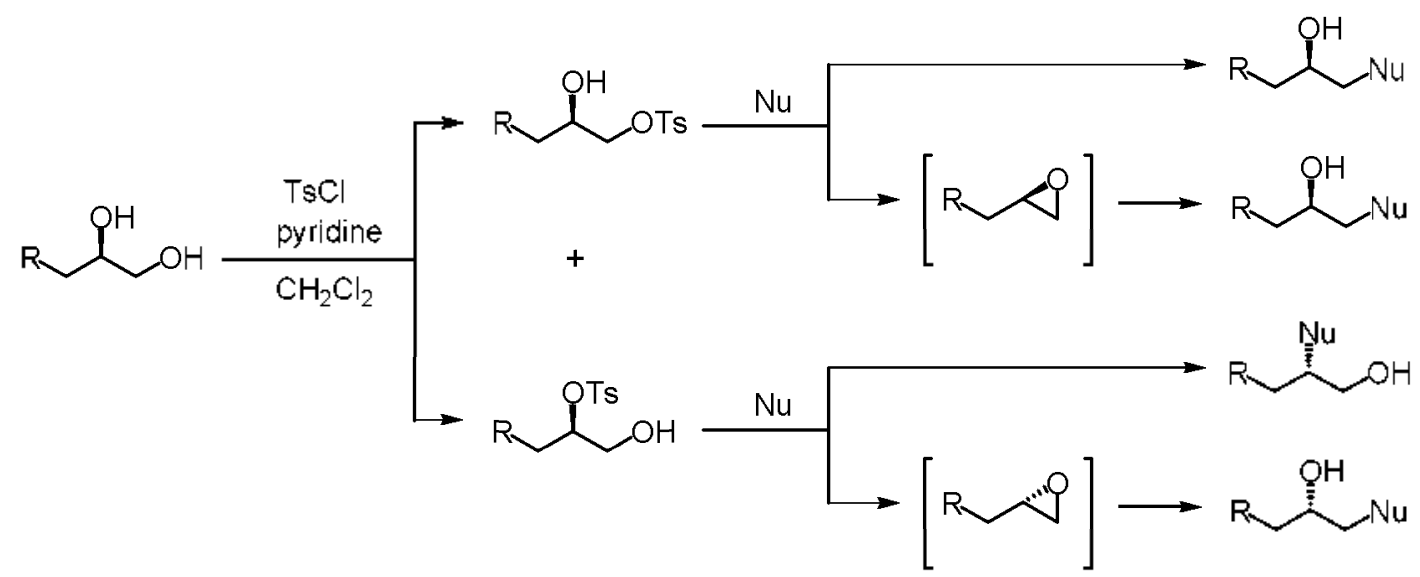

Scheme 3

product. which would be detected and dealt with. The twostep pathway from the minor mono-2-tosy late compound. on the other hand. produces the 2-hydrosy-1-substituted product that is optically antipodal to the desired product. Therefore. when the regioselectivity is not very high in the mono tosylation step and the two regioisomeric mono tosylate compounds are not completely separated before the subsequent nucleophilic substitution reaction one may end up with an enantiomerically impure product from an optically pure diol starting material. ${ }^{4}$ Clearly. a more efficient and stereochemically reliable method would be welcome for the transformation in question. We report herein a regioselective Mitsunobu-tosylation of 1,2-diols, which, when coupled with a subsequent nucleophilic substitution, offers an alternative pathway.

The Mitsunobu reaction is widely used in the synthetic chemistry. ${ }^{3}$ Since the initial report. a growing list of nucleophiles that can be employed in the reaction has expanded its synthetic utilities. Tosylation under the Mitsunobu conditions

Table 1. The Mitsunobutosylation of diols. ${ }^{\sigma}$

\begin{tabular}{|c|c|c|c|c|c|}
\hline entry & diol & $\begin{array}{l}\text { C-2 mono } \\
\text { tosylate }(\%)\end{array}$ & $\begin{array}{l}\mathrm{C}-1 \text { mono } \\
\text { tosy late }(\%)\end{array}$ & $\begin{array}{c}\text { Recovered } \\
\text { diol }(\%)\end{array}$ & $\begin{array}{c}\text { Reaction } \\
\text { time }\end{array}$ \\
\hline 1 & & $77^{b}$ & a trace & 18 & $4 d$ \\
\hline 2 & & 64 & 0 & 5 & $2 \mathrm{~d}$ \\
\hline 3 & & 51 & 15 & 22 & $7 \mathrm{~d}$ \\
\hline 4 & & 34 & 32 & 34 & $6 \mathrm{~d}$ \\
\hline 5 & & 50 & 0 & 9 & $2 \mathrm{~d}$ \\
\hline 6 & & 0 & 54 & 35 & $6 \mathrm{~d}$ \\
\hline 7 & & 23 & 22 & - & $1 \mathrm{~d}$ \\
\hline
\end{tabular}


is unique: ${ }^{6}$ not only does it yield a synthetically useful intermediate. its stereochemistry is opposite to that produced under more general tosylation conditions ( $\mathrm{TsCl} / \mathrm{py}$ ridine) therefore the two tosy lation methods (Mitsunobu ws. TsCl/py ridine) are complementary to each other.

Mitsunobu reactions of vicinal diols have been reported to show interesting patterns of regioselectivity. "With 1.2-diols. Mitsunobu-benzoylations take place selectively at the more hindered C-2 hydroxyl group. The selectivity was rationalized by invoking a cyclic intermediate formed between 1.2-diols and phosphine. With 2.3-dilydroxy esters, an exclusive selectivity has been reported for the reactions at $\mathrm{C}-3$. In our efforts to search for an efficient and stereochemically reliable method for mono-substitution at C-I of 1.2-diols. we turned our attention to the Mitsunobu-tosylation.

Of the several forms of the tosylate nucleophile reported in the Mitsunobu reaction. we selected to use py ridinium tosy late in the initial stage of our study. Pyridinium tosylate has been reported to produce regioselective Mitsunobu-tosylations with 2.3-dilydroxy ester substrates. ${ }^{\text {ff }}$ Indeed. the reaction with 1.2 decanediol in the presence of triphenylphosphine (TPP), diethyl or diisopropyl azadicarboxy late (DEAD or DIPAD) and pyridinium tosy late (PPTS) resulted in a regioselective tosylation at C-2 hydroxyl group. Subsequent optimizations led to the following reaction conditions: diol : PPTS : TPP : DIPAD = $1: 2: 2: 1.5$ in THF as the solvent. Under these conditions. 1.2-decanediol was converted to the corresponding secondary tosy late in $77 \%$ yield after 4 days at it, with only a trace of primary tosylate and no di-tosy late product formed ( $18 \%$ of the starting diol was also recovered, entry 1 . Table 1). A parallel reaction using triethylammonium tosylate under otherwise identical conditions produced inferior results ( $30-40 \%$ yield). Interestingly. when monolydroxy compounds. either primary or secondary. were the substrates the two tosy late counter cations didn't show any significant difference in yields or reactivities. Therefore the acidity difference in the two forms of tosylate nucleo- philes appears to have any effects with 1,2-diol substrates only. The observed superiority of pyridinium over less acidic triethylammonium cation is consistent with the proposed mechanism involving a cyclic intermediate formed with 1.2-diol substrates.

A series of diols was then subjected to the optimized Mitsunobu-tosylation conditions (Table 1). It was observed that the reactivity and regioselectivity were very much dependent on the steric and electronic factors of the substrates. 1.2-Diol substrates with a single substituent at C-3. either alkỵl or aryl. undervent the Mitsunobu-tosylation to yield the secondary mono tosylate products exclusively (entries 1.2 and 5 ). When an alkyl branching existed at C-3, the Mitsunobu-tosylation at the favored secondary hydroxyl group was hindered. resulting in a decreased yield and a lower regioselectivity (entry 3). Electronegative substituents were observed to have a big influence: with an alkoxy group at C-3. the preference for C-2 hydrosyl group completely disappeared. and the yield was also low (entry 4). Interesting to note is that an aryl ring. a slightly electron-withdrawing group, at $\mathrm{C}-3$ didn't show nuch negative effects for the Mitsunobu-tosylation at C-2 (entry 2), neither did an alkoxy group at C-4 (entry 5). With a more electronegative oxo group at C-3. the Mitsunobu-tosylation now exhibited a completely reversed regioselectivity for the primary hydrosyl group (entry 6). This is consistent with the general preference for the $\beta$-hydroxyl group in Mitsunobu reactions of $\alpha, \beta$-dihydroxy esters. "Noteworthy is that this preference for the $\beta$-hydroxyl group was upheld even when it was a primary hydroxyl group. Finally, a 1.3-diol failed to show any regioselectivity (entry 7).

While the Mitsunobu-tosylation of 1.2-diols shows a regioselectivity opposite to that of more general tosy lation reaction using $\mathrm{TsCl} / \mathrm{py}$ ridine ( $\mathrm{C}-2$ for the former and $\mathrm{C}-1$ hydroxyl group for the latter). when the tosylation reaction is to be followed by a nucleophilic substitution reaction, both tosylation methods can eventually yield the identical 2-hỵdroxy-

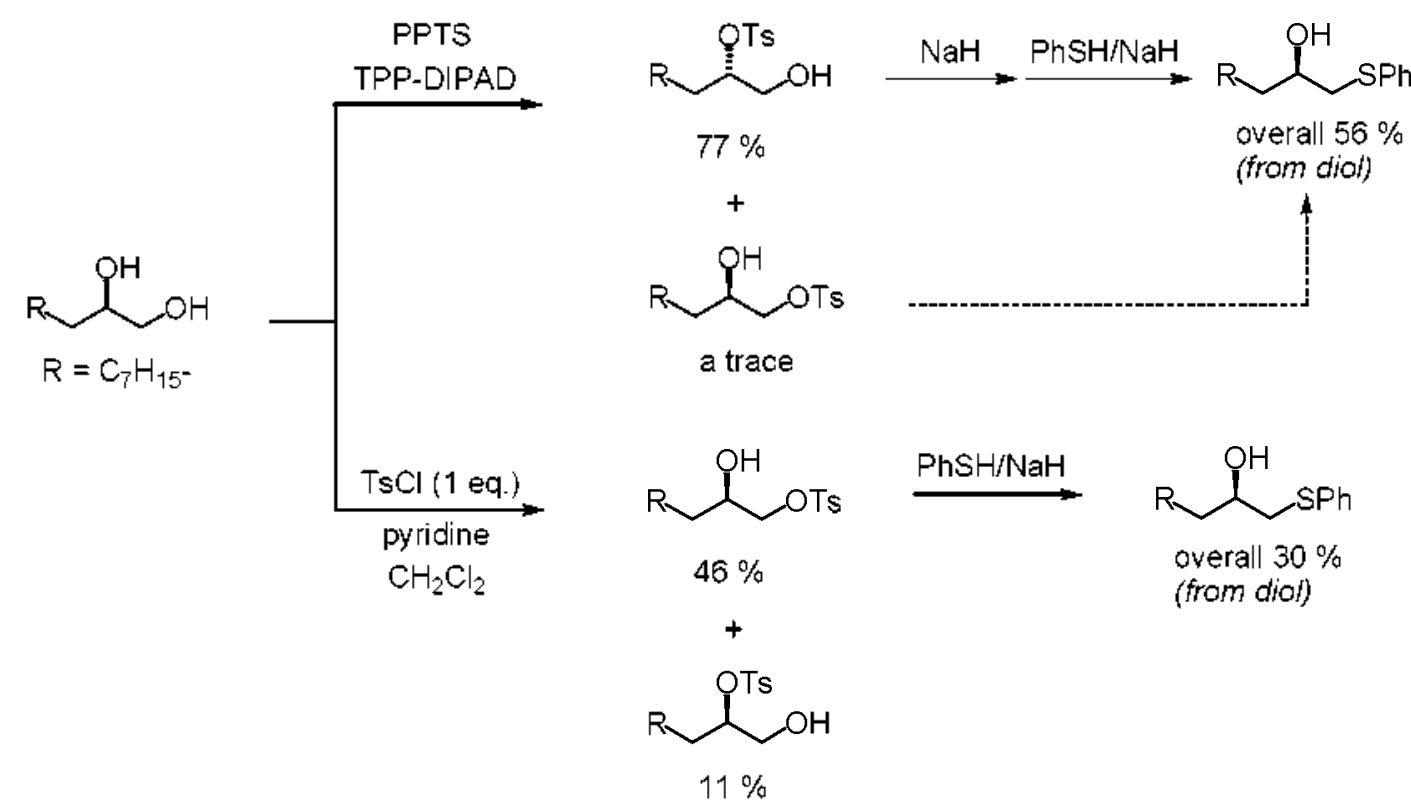

Scheme 4 
1-substituted product. With the Mitsunobu-tosy lation product (1-hydroxy-2-tosty late) the subsequent nucleophilic substitution reaction is performed in a two-step. one-pot reaction. Thus. (S)-1-hydroxy-2-decyl tosylate, prepared via Mitsunobutosy lation of $(R)$-1 2-decanediol, was treated with $\mathrm{NaH}$ in THF (scheme 4). When all the starting material had been consumed, a nucleophile (NaSPh) was added. After acidic work-up. $(R)$ 1-phenylthio-2-decanol was isolated in $73 \%$. or $56 \%$ overall yield (counting from the diol starting material). Due to the low regioselectivity of the $\mathrm{TsCl} / \mathrm{py}$ ridine tosylation method. the same 1-phenylthio-2-ol product (the same $R$-enantiomer) was obtained in only $30 \%$ overall yield when the more general tosylation method was employed. Furthermore. the Mitsunobutoșylation pathway offers a definite advantage over the conventional TsCl/py ridine tosylation method in terms of the stereochemical reliability. As discussed earlier (Scheme 3), each of the two regioisomeric tosylate products obtained from the $\mathrm{TsCl} /$ pyridine reaction may lead to a $\mathrm{C}-1$ substitution product optically antipodal to each other. In contrast. the Mitsunobultosylation is accompanied by an inversion of configuration at the reacting carbinol carbon, and when it is coupled with a subsequent two-step. one-pot nucleoplilic substitution reaction at $\mathrm{C}-1$, the overall conversion for either regioisomer involves a double inversion or net-retention of configuration at the $\mathrm{C}-2$ stereocenter (Scheme 4), ${ }^{8}$ Therefore. a low regioselectivity in the Mitsunobu-tosylation or an incomplete separation of the regioisomeric tosylate products would not impair the stereochemical integrity of the starting diol. In this regard. the Mitsunobu-tosylation of 1.2-diols is reminiscent of the classical procedure for converting vic-diols to epoxides stereospecifically. ${ }^{9}$

In conclusion. the Mitsunobu-tosylation of 1,2-diols has been found to be selective for the reaction at $\mathrm{C}-2$ when no steric/electronic bias exists. When this reaction is coupled with a subsequent two-step. one-pot nucleophilic substitution reaction, the pathway represents an efficient and stereochemically reliable altemative to the conventional $\mathrm{TsCl} / \mathrm{pyr}$ ridine method for mono-substitution at C-I of 1.2-diols.

\section{Experimental Part}

Mitsunobu-tosylation of $(R)$-1,2-decanediol (General procedure). (R)-1.2-Decanediol (170 $\mathrm{mg} .1 \mathrm{mmol}$ ) and PPTS (506 mg. $2 \mathrm{mmol}$ ) were dissolved in anhydrous THF (2 mL). TPP ( $524 \mathrm{mg} .2 \mathrm{mmol}$ ) was added as a solution in THF $(2.5$ $\mathrm{mL})$. The mixture was cooled in an ice bath. DIPAD $(0.295$ $\mathrm{mL}, 1.5 \mathrm{mmol})$ in THF $(0.5 \mathrm{~mL})$ was added and the mixture was stirred at 0 " $\mathrm{C}$ for $10 \mathrm{~min}$. before it was warmed to $\mathrm{rt}$ and stirred for 4 days. The mixture was diluted with ethyl acetate and washed with $10 \% \mathrm{NaHCO}_{3}$. then with brine. After drying $\left(\mathrm{Na}_{2} \mathrm{SO}_{4}\right)$ and concentration. the crude product was purified by column chromatography (hexane-EtOAc $2: 1$, then 1:2). then by crystallization (EtOAc-hexane) to yield (S)-1-hydroxy-2-decyl tosylate $(253 \mathrm{mg}, 77 \%)$. $[\alpha]=-9.0$ (c 2.23 . $\mathrm{EtOH}):{ }^{\mathrm{H}} \mathrm{H} \mathrm{NMR}\left(\mathrm{CDCl}_{3}\right)$ ò $7.82(2 \mathrm{H}, \mathrm{d} . J=7.5 \mathrm{~Hz}) .7 .35(2 \mathrm{H}$. d. $J=7.5 \mathrm{~Hz}), 4.61-4.55$ (1H. m). $3.73-3.68(2 \mathrm{H} . \mathrm{m}), 2.46$ (3H. s), $2.07(1 \mathrm{H}, \mathrm{t} . J=6.3 \mathrm{~Hz}) .1 .60-1.56(2 \mathrm{H}, \mathrm{m}) .1 .33-1.16$ $(\mathrm{l} 2 \mathrm{H}, \mathrm{m}), 0.88(3 \mathrm{H}, \mathrm{t} . J=6.3 \mathrm{~Hz})$.
(R)-1-Phenylthio-2-decanol. (S)-1-Hydroxy-2-decyl tosylate (156 mg. $0.48 \mathrm{mmol}$ ) was dissolved in DMF (5 mL) and $\mathrm{NaH}$ (55\%. $73 \mathrm{mg} .1 .7 \mathrm{mmol}$ ) was added. The mixture was stirred at $\mathrm{rt}$ for $2 \mathrm{hr}$. In a second flask, in the mean time, $\mathrm{PhSH}(0.102$ $\mathrm{mL}, 1 \mathrm{mmol})$ was dissolved in DMF $(10 \mathrm{~mL})$ and $\mathrm{NaH}(55 \%$. $73 \mathrm{mg} .1 .7$ numol) was added. This nixture was heated to $120^{\circ} \mathrm{C}$ for 2 hrs. then cooled to rt. The PhSNa solution thus prepared was added to the first flask and the nuxture was stirred at $\mathrm{rt}$ for $1.5 \mathrm{hr}$. The mixture was concentrated and the residue was dissolved in EtOAc. It was washed with $10 \%$ aq. citric acid. then with brine. After drying $\left(\mathrm{Na}_{2} \mathrm{SO}_{4}\right)$ and concentration, the crude product was purified by column chromatography (hexaneEtOAc 5:1) to yield $(R)$-1-phenylthio-2-decanol ( $93 \mathrm{mg}, 73 \%$ ). $[\alpha]=18.3(c 3.17, \mathrm{EtOH}):{ }^{l} \mathrm{H}$ NMR $\left(\mathrm{CDCl}_{3}\right) \delta 7.41-7.36(2 \mathrm{H}$, m). $7.33-7.18(3 \mathrm{H}, \mathrm{m}), 3.68-3.65(\mathrm{lH}, \mathrm{m}) .3 .16(\mathrm{lH}, \mathrm{dd}, J=$ $2.5 .12 .5 \mathrm{~Hz}), 2.84$ (1H. dd. $J=7.5,12.5 \mathrm{~Hz}), 2.38(1 \mathrm{H}, \mathrm{d} . J=$ $2.5 \mathrm{~Hz}) .1 .5 \mathrm{l}-1.49(2 \mathrm{H}, \mathrm{m}), 1.45-1.26(12 \mathrm{H}, \mathrm{m}), 0.87(3 \mathrm{H} . \mathrm{t} . J=$ $6.3 \mathrm{~Hz})$.

Aclonowledgments. This work was supported by the Korea Research Foundation Grant funded by the Korean Government (MOEHRD. Basic Research Promotion Fund. KRF2006-C00379).

\section{References and Notes}

1. Reviews: (a) Shibasaki, M, Kanai, M. Eun J. Org. Chem. 2008, 1839. (b) Farina, V; Brown, S. D. Angew. Chem. Int Ed. 2006, 45,7330

2. O Donnell, C. I.: Burke, S. D. J. Ong Chem 1998, 63,8614

3. For functionalization of diols after Sn-activation, see: (a) David, S.: Hanessian, S. Tetrahedron 1985, 41, 643. (b) Boons, G.-T.; Castle, G. H.; Clase, A.; Grice, P.; Ley, S. V.; Pinel, C. Syntent 1993, 913. (c) Martinelli, M. J.: Nayyar, N. K.; Moher, E. D.; Dhokte, U. P.: Pawlak, J. M.: Vaidyanathan, R. Oig. Lett. 1999. 1,447 .

4. Clink, R. D.; Forsyth, C. J. J. Ong. Chem. 1995, 60, 8122.

5. (a) Mitsunobu, Z. O. Symthesis 1981, 1, 1. (b) Hughes, D. L. Organic Reaction: Beak, P. et al., Eds.: John Wiley \& Son: New York, 1992; vol. 42, p 335-656. (c) But, T. Y. S.; Tov, P. H. Chent. Asian J. 2007, 2, 1340.

6. (a) Galynker, I.: Still, W. C. Tetrahedron Lett. 1982, 23, 4161 (b) Anderson, N. G.; Lust, D. A.; Colapret, K. A.; Simpson, J. H.; Malley, M. F.; Gougoutas, J. Z. J. Org. Chent 1996,61,7955. (c) Loibner, H, Zbbiral, E. Hell Chin Acta 1976, 59, 2100.

7. (a) Pautard, A. M. Evar1s, S. A. Ir., J. Org. Chem. 1988, 53, 2300. (b) Pantard-Cooper, A.: Evans, S. A. Ir., J. Org. Chem. 1989, 54, 2485 . (c) Pautard-Cooper, A.: Evans, S. A. Jr., Kenan, W. R. Tetrahedron 1991, 47, 1603. (d) Camp, D.; Tenkins, I. D. J. Org. Chent 1989, 54, 3045. (e) He, L.; Wanunu, M.; Byun, $\mathrm{H}$. S.: Bitman, R. J. Org. Chem 1999, 64, 6049 (f) Ko, S. Y.J. Ong. Chem. 2002, 67, 2689. (g) Wang, G.: Ella-Menye, J-R.; St. Martin, M.; Yang, H.; Williams, K. Org. Lett. 2008, 10, 4203.

8. The stereochemical courses of the Mitsunobu-tosylation (a complete inversion at C-2) and the subsequent two-step. one-pot, $\mathrm{PhS}^{-}$-substitution reaction (a complete inversion at C-2) have been confinmed by HPLC and optical rotation data.

9. (a) Golding, B. T; Hall, D. R.; Sakrokar, S. J. Chem. Soc, Perkin Trons 1 1973, 12l4 (b) Kolb, H. C. Sharpless, K. B. Tetwahedron $1992,48,10515$, (c) Kolb. H. C.: VanNienwenhze, M S.: Sharpless, K. B. Chem Rev 1994, 94, 2483. (d) Liang. T.: Moher, E. D.; Moore, R. E.; Hoard, D. W. J. Org. Chem. 2000, 65, 3143. (e) Jang, D. O.; Joo, Y. H.; Cho, D. H. Synthetic Communt 2000, 34 , 4489. 